\title{
Investigating Digital Distraction among Pre-service Science, Technology, and Mathematics Teachers in Nigeria
}

\author{
Adeneye 0. A. Awofala \\ aawofala@unilag.edu.ng \\ University of Lagos, Nigeria \\ Oladiran S. Olabiyi \\ solabiyi@unilag.edu.ng \\ University of Lagos, Nigeria
}

Awoyemi A. Awofala

awofalaaa@tasued.edu.ng

Tai Solarin University of Education, Nigeria

\author{
Omolabake T. Ojo \\ otojo@unilag.edu.ng \\ University of Lagos, Nigeria
}

Racheal O. Okunuga

rokunuga@unilag.edu.ng

University of Lagos, Nigeria

\author{
Abisola 0. Lawani \\ lawaniao@tasued.edu.ng \\ Tai Solarin University of Education, Nigeria
}

\begin{abstract}
Internationally, the proliferation of digital technologies in classrooms has produced digital distractions among digital natives in this $21^{\text {st }}$ century. Thus, it is highly imperative to develop a suitable instrument for assessing and measuring digital distraction among higher education students to enable continuing research and practice. While previous studies had treated and measured digital distraction as a sub-component of a multi-dimensional construct and as a test, the present study through instrumentation survey research, developed and authenticated a standalone digital distraction scale among pre-service science, technology and mathematics (STM) teachers in Nigeria. The instrument is constructed by adopting a multidimensional standpoint of digital distraction around a higher-order modelling method. The pre-service STM teachers were recruited from a culturally varied university student population in Nigeria. The results showed a high level of digital distraction among the pre-service STM teachers in Nigeria and the digital distraction is composed of several connected yet distinctive factors (emotional distraction, digital addiction, and distraction by procrastination), with proof backing up a higher-order structural archetypal. More so, empirical evidence confirmed the measurement invariance of the scale with regards to gender and the consistency of the psychometric properties of the digital distraction scale. Finally, test-retest reliability of the digital distraction scale showed that the scores are not variable over time and that the scale is not sensitive to alterations in the learning milieu. Finally, it is hoped that this tool will be handy for educators interested in isolating pre-service STM teachers at risk of high digital distraction
\end{abstract}


which may cause lack of respect and privation of courtesy for instructors and personal distraction in the classroom.

\section{Keywords}

Digital distraction, scale, pre-service teachers, science, mathematics, technology, Nigeria

\section{Introduction}

Worldwide, in this $21^{\text {st }}$ century, the proliferation of digital technologies has produced digital distractions among the digital natives, in particular, the higher education students. McCoy (2016) found that American Millennial Generation students expended an average of $20.9 \%$ of class time deploying a digital device for non-class purposes including texting, social networking, and emailing and that the average participant deployed a digital device 11.43 times for non-class purposes during a typical school day in 2015 compared to 10.93 times in 2013 (McCoy, 2013). Among employees, digital distraction has reduced efficiency and wore down office good manners (PR Newswire, 2013). Although digital technologies are precious in pedagogical discourse (Wen, Tsai, Lin, \& Chuang, 2004), they can as well act as an obstacle if students deploy them to activities unconnected to their schoolwork. There is a shred of compelling evidence that higher education students utilize digital technologies in classroom for activities unrelated to their classwork thereby causing their underachievement in learning (Burns \& Lohenry, 2010; Rajeshwar, 2010; Hefferman, 2010). This use of digital technologies by students in things unrelated to classwork in the classroom causes digital distraction (Chen, Nath, \& Insley, 2014) which has been found to correlate negatively with self-reported comprehension of course material and course performance (Martin, 2011; Junco \& Cotton, 2011; Frisby, Sexton, Buckner, Beck, \& Kaufmann, 2018). It is argued that most of the popular studies that support the use of digital technologies in the classroom assess success through students' perceptions (e.g. satisfaction) reasonably than adopting an objective measure of learning (Chen et al., 2014). Thus, some studies have shown that unfettered access to digital technologies in the classroom causes poor learning outcomes in students (Kraushaar \& Novak, 2010; Junco \& Cotton, 2011; Martin, 2011).

The study by Duncan, Hoekstra, and Wilcox (2012) showed a significant negative relationship between in-class phone use and final grades, with the use of cell phones corresponding to a drop in students' grades. This result implies that students cannot multitask nearly as effectively as they think they can (Ophir, Nass, \& Wagner 2009). Precisely, students restrained from utilizing digital technologies in the classroom performed better in learning than students who had unfettered access to digital technologies (Martin, 2011; Wood, Zivcakova, Gentile, Archer, Pasquale, \& Nosko, 2012). Contrastingly, research evidence suggests that a student may be multitasking in the classroom with a digital device and still not being distracted during the pedagogical discourse (McCoy, 2016). This has made Sullivan, Johnson, Owens and Conway (2014) to categorize students' deployment of digital devices for non-class purposes as a "low-level disruptive behaviour". They argued that instructors could derive maximum advantage from comprehending how the classroom ecosystem filled with digital technologies can have impacts on student learning engagement, reasonably than paying attention to correcting fruitless behaviour.

However, stakeholders in the tertiary education setting particularly the educators and managers have attained meagre success in providing the appropriate schemes to decreasing digital distraction and boost the progressive and productive facets of digital technologies in the classrooms (Melerdiercks, 2005). The digital distraction in this $21^{\text {st }}$ century can be likened to the television generation era of the $20^{\text {th }}$ century with today's students being part of a 'virtual generation' who were born as digital natives and grew up with a background controlled by the 
internet and digital technologies that are promoting paradigm shifts in pedagogical discourse. These shifts in pedagogical discourse imply that the customary or traditional educational philosophies and strategies need to change and adjust to the technology-opulent and informationdriven milieu that characterize the present $21^{\text {st }}$-century world. This attempt should kick-start with a rich comprehension of the underlying sources of digital distraction in the classroom.

Digital distractions are those personal behaviours that put to test, challenge, disrupt and interfere with the thoughtfulness, concentration and information processing of an individual using digital technologies. As digital technologies become ubiquitous in this globally connected world, digital distractions are becoming prevalent in higher education classrooms that are permissive of digital technologies. Digital distraction influences students' cognitive processing capability negatively (Attia, Baig, Marzouk, \& Khan, 2017) when challenging content is taught using poor pedagogy (Frisby et al., 2018) thereby hampering digitally distracted students' skills to process information and create the schema (Sweller, van Merrienboer, \& Pass, 1998). Responding to digital distractions in the classroom, many higher institutions dons are being forced to implement a total embargo on digital technology adoption by students during pedagogical discourse (Adams, 2006; Melerdiercks, 2005). This they do to engender a conceptual understanding of the content being taught (Awofala, 2017) and promote classroom etiquette full of respect and courtesy while not undermining creativity in the classroom (Awofala \& Fatade, 2015).

To increase students' conceptual learning of content and detect students who possess the greatest risk of digital distraction in the classroom, conceptualization and measurement of digital distraction must be done appropriately. Today there is a paucity of research in this area as a digital distraction is measured as part of the dimensions of an underlying construct. For instance, digital distraction has been assessed and measured as part of a scale for measuring problematic Internet use (Davis, Flett, \& Besser, 2002). This has made it impossible not only to ascertain the dimensionality of the construct but to determine the degree of psychometric support for this construct. More so, researchers are divided on whether to measure digital distraction using a test or a scale. Greenfield (2017) conceptualized digital distraction as a 12-item test involving yes or no while Davis et al (2002) measured distraction as part of the online cognition scale using a survey involving seven items on a seven-point Likert scale. This inconsistency in measurement may imply defining the construct appropriately.

It is urgently important in this digital age that effort is concentrated on evolving and developing an appropriate instrument for measuring digital distraction for the dual purpose of research and practice. The lack of dimensional perspective has brought about the inability to investigate predictors and outcomes of digital distraction. This obstructs researcher capability to detect those students who have the greatest risk for digital distraction and to develop more directed and nuanced mediations for reducing student digital distraction in the classroom. Chen et al., (2014) used one item to assess digital distraction in their study without giving information regarding its reliability. The only reliable and valid scale for measuring distraction was the one developed by Davis et al (2002). The scale did not measure digital distraction per se, but assessed distraction related to online and internet activities. It is a seven-item unidimensional subscale of an online cognition scale with Cronbach alpha coefficient of 0.81 (Davis et al., 2002). However, the items used to measure distraction in the online cognition scale did not match conjectural conceptualization of digital distraction of the present $21^{\text {st }}$ century. The seeming difference in the measurement and characterization of digital distraction has made it difficult to associate results across studies and infer deductions regarding the precursors and consequences of digital distraction.

This present study fills this lacuna in the literature by examining the psychometric properties of a newly developed scale focusing on digital distraction among Nigerian pre-service science, technology and mathematics (STM) teachers. Pre-service STM teachers were preferred to 
secondary school students because of their ubiquitous use of digital technologies in the classroom and that they fall within the age bracket of avid users of digital technologies (McCoy, 2013; 2016). Older teachers are less receptive in using digital technologies and less keen and less excited in deploying digital technologies in the classroom (O'bannon \& Thomas, 2014). While Gebre, Saroyan and Bracewell (2014) established that students' cognitive and social engagement in technologyopulent classrooms is meaningfully correlated to their instructors' perceptions of teaching effectiveness, they remarked that the implementation of technology in teaching in the university should necessitate the incorporation of staff advancement programmes connected to transforming instructors' formations of teaching effectiveness (Awofala, 2012). Premeditated adoption of digital technologies in STM education can augment and enhance the learning of scientific, mathematical, and technological processes and expertise about the expansion of advanced proficiencies in STM learning (Rutten, van Joolingen \& van der Veen 2012; Hegedus \& Roschelle 2013).

Developing a reliable and valid scale for measuring pre-service STM teachers' in-class digital distraction during learning will help to isolate cases of a mobile addict during pedagogical transactions in the classroom. This would also add to the body of lean literature on digital distraction as researchers would be able to establish predictors and outcomes of digital distraction in the classroom. The particular validation measures comprise exploratory and confirmatory factor structure and Cronbach alpha and test-retest analyses of the in-class digital distraction scale.

\section{a. Research Questions}

(1) What is the level of digital distraction among the pre-service STM teachers in Nigeria?

(2) How construct valid are the items of the digital distraction scale among the pre-service STM teachers in Nigeria?

(3)What are the internal consistency estimate and the test-retest reliability of the digital distraction scale among the pre-service STM teachers in Nigeria?

(4) Does the digital distraction scale show measurement invariance with regards to the gender of the pre-service STM teachers in Nigeria?

(5) What are the relationships among distraction by procrastination, emotional distraction, digital addiction and aggregate digital distraction of pre-service STM teachers?

\section{Method}

\section{a. Research Design}

This study adopted an instrumentation survey research which is the type of research that focuses on the unveiling of new or revised content, procedure, technologies or instruments for academic and educational practice (Awofala, 2012; Ogunniyi, 2004).

\section{b. Participants}

The population of this study comprised pre-service STM teachers at the Department of Science and Technology Education, the University of Lagos in Nigeria. Table 1 showed a sample of the participants involved in the study. It also showed the gender composition, the course of study, the age distribution and the grade level of the sample. There are seven programmes of study in the Department of Science and Technology Education, University of Lagos, Nigeria. All participants were volunteers and no course credits were given for their participation. The sample was homogeneous-participants were primarily Nigerians, and all were English speaking. Moreover, all 
had taken an introductory computer science course in their 100 level or as a general course in their 200 level for direct entry students. All participants reported ready access to computers at the university and had smartphones.

\begin{tabular}{|c|c|c|c|}
\hline Grade Level & $(\%)$ & male (\%) & female $(\%)$ \\
\hline First-year & $714(30.00)$ & $353(49.44)$ & $326(50.56)$ \\
\hline Mean $_{a g e}=19.3$ years & $\mathrm{SD}_{\mathrm{age}}=2.3$ years & \multicolumn{2}{|c|}{ Age range $=16-25$ years } \\
\hline Second-year & $575(24.16)$ & $284(49.39)$ & $291(50.61)$ \\
\hline Mean $_{a g e}=21.4$ years & $\mathrm{SD}_{\mathrm{age}}=2.4$ years & \multicolumn{2}{|c|}{ Age range $=17-30$ years } \\
\hline Third-year & $555(23.32)$ & 273 (49.19) & $282(50.81)$ \\
\hline Mean $_{a g e}=22.3$ years & $\mathrm{SD}_{\mathrm{age}}=2.2$ years & \multicolumn{2}{|c|}{ Age range $=18-32$ years } \\
\hline Fourth-year & $536(22.52)$ & $265(49.44)$ & $271(50.56)$ \\
\hline Mean $_{\text {age }}=23.8$ years & $\mathrm{SD}_{\mathrm{age}}=2.6$ years & \multicolumn{2}{|c|}{ Age range $=19-34$ years } \\
\hline Age distribution & $(\%)$ & & \\
\hline Below 20 years & $1090(45.80)$ & & \\
\hline 20-34 years & $1290(54.20)$ & & \\
\hline Programme of study & $(\%)$ & & \\
\hline B.Sc(Ed) Biology & $580(24.37)$ & & \\
\hline B.Sc(Ed) Mathematics & $440(18.49)$ & & \\
\hline B.Sc(Ed) Physics & $200(8.40)$ & & \\
\hline B.Sc(Ed) Technology & $280(11.76)$ & & \\
\hline B.Sc(Ed) Home Economics & $300(12.61)$ & & \\
\hline B.Sc(Ed) Chemistry & $300(12.61)$ & & \\
\hline \multirow[t]{2}{*}{ B.Sc(Ed) Integrated Science } & $280(11.76)$ & & \\
\hline & f $\quad(\%)$ & & \\
\hline Total Sample & $2380(100)$ & & \\
\hline Male & $1175(49.37)$ & & \\
\hline Female & $1205(50.63)$ & & \\
\hline
\end{tabular}

Table 1. Participants' demographic data

\section{c. Construction of the digital distraction scale among pre-service STM teachers}

First, in the construction of the DDS, relevant extant literature was reviewed to pull together conceptualisations of digital distraction and prior assessment tools from which probable items could be adapted for utilization. Second, focus groups and open-ended interviews with 80 pre-service STM teachers were conducted to acquire how they intellectualized digital distraction in class. The data collected from the interviews produced an inclusive list of indicators of digital distraction. Third, a preliminary list of 30 pre-service STM teacher-report items was developed. Fourth, the expert validation process was carried out on the items to ensure that the items did not deviate from the digital distraction construct. Finally, a cognitive pretesting process was carried out with 
pre-service STM teachers to make sure that the items did not deviate from the intended comprehension and interpretation. This procedure produced 21 pre-service STM teachers-report items. The digital distraction scale has 21 items (5 positive statements and 16 negative statements) that are all ordinal on a modified 5- point Likert scale ranging from 0-Undecided, 1Strongly agree, 2- Agree, 3-Disagree to 4- Strongly disagree for negative statements while the reverse was the case for positive statements with the undecided as to the starting point in both cases.

\section{d. Procedures}

A letter was written to the Head, Department of Science and Technology Education, University of Lagos, Nigeria for permission to use the pre-service STM teachers for research. After obtaining the consent, appointments were scheduled with the pre-service STM teachers and they were informed on the purpose of the study without being coerced to attempt the survey as participation was made voluntary. Thereafter, the pre-service STM teachers were administered with the DDS and the participants were applauded for taking part upon completion of the survey.

\section{e. Data analysis}

Research question one was answered using mean and standard deviation. Research question two was answered using exploratory and confirmatory factor analyses. Research question three was answered using Cronbach alpha and Pearson moment correlation coefficients. Lastly, research questions four and five were answered using confirmatory factor analysis and Pearson productmoment correlation coefficient respectively.

\section{Results}

a. Research Question One: What is the level of digital distraction among the pre-service STM teachers in Nigeria?

In the digital distraction scale, the score ranged from 0 to 4 . A score of 2 is the middle point so higher scores indicate high digital distraction. Of 2380 pre-service STM teachers, 350 (14.71\%) had scores less than $2(M=1.46, S D=0.24$, score range: $1.00-1.89,95 \% C I=1.44-1.49)$, 1839 $(77.27 \%)$ had scores greater than $2(M=2.82, S D=0.44$, score range: $2.11-4.00,95 \% C I=2.80-$ 2.84), while $191(8.03 \%)$ had scores equaled $2(M=2, S D=0$, score range: $2.00,95 \% C I=2.00)$. $A$ large proportion of these pre-service STM teachers had a high digital distraction. However, the overall $M=2.56, S D=0.64$, score range: $1.00-4.00$, and $95 \% C I=2.53-2.58$ for the entire sample showed high digital distraction of pre-service STM teachers. Table 2 showed the descriptive statistics of the items in the DDS.

b. Research Question Two: How construct valid are the items of the digital distraction scale among the pre-service STM teachers in Nigeria?

Two analytical data reduction procedures were conducted in this study. First, exploratory factor analysis (EFA) was used to explore the probable primary factor structure of the multidimensional Digital Distraction Scale without imposing a predetermined structure on the scale. Second, confirmatory factor analysis (CFA) was deployed to verify and confirm the factor structure of the multidimensional Digital Distraction Scale identified in the exploratory factor analysis. 


\section{Exploratory Factor Analyses}

Before the conduct of EFA, descriptive statistics of each of the items of DDS were figured, together with mean, standard deviation, skewness, and kurtosis. Critical scrutiny of the descriptive statistics indicated that all variables in the EFA model did not deviate from a normal distribution with the values of skewness and kurtosis falling in the acceptable range -3 to +3 . Further scrutiny of the input data revealed their appropriateness as established by Bartlett's test of sphericity, $x^{2}=4$. 810E3; $d f=36 ; p<.001$ which put to test the null hypothesis that the correlation matrix is an identity matrix. The Kaiser-Meyer-Olkin measure of sampling adequacy (MSA) was within satisfactory range (values of .60 and above) with a value of .762. Each of the variables in the model was greater than the threshold value of (.60) of MSA which vacillated from .686 to .857 . However, virtually all the partial correlations were small as revealed by the anti-image correlation matrix. All these procedures led to the supposition that the set of 9 items of DDS was suitable for PCA. To examine the factorial validity of this new scale, DDS, EFA using principal components analysis with varimax rotation was adopted. Because this study tested the hypothesis about the factor to be mined, the PCA was carried out to resolve the number of dimensions to be retained in the DDS subcategories. For the DDS, an inspection of the eigenvalues and scree plot reinforced a three-dimension model. The first dimension explained $36.05 \%$ of the variance, although the second and the third dimensions explained $12.58 \%$ and $12.03 \%$ correspondingly. These dimensions epitomise emotional distraction, digital addiction and distraction by procrastination, correspondingly. All the three subcategories explained $60.66 \%$ of the variance.

Nevertheless, 12 items have plummeted in the long run either because they loaded on more than one factor or that they failed to load on the intended factor. The following items loaded on more than one factor (DDS3: I always find myself expending more time with virtual or online friends than real people close-by. DDS5: I covertly wish I could be a little less wired or connected to my digital devices. DDS6: I am fond of sleeping with my digital devices (e.g smartphones) ON under my pillow or very close to my bed. DDS8: I find myself texting, emailing, tweeting or surfing on my digital devices while driving or doing other similar activities that demand my focused dedication and attentiveness. DDS10: Sometimes I feel ill-at-ease or uncomfortable when I unintentionally leave my digital devices (e.g. smartphones) in the car or at home, even if there is no internet connectivity. DDS12: I eat meals with my digital devices (e.g. smartphones) as part of the table place setting always). The following failed to load on the intended factor (DDS14: Any time I leave the house my digital devices (e.g. smartphones) are ALWAYS with me. DDS15: When I am using my digital devices I don't meditate on my responsibilities. DDS16: When I am less busy, I use my digital devices. DDS17: I find that I use my digital devices more when I should be doing something else. DDS18: When I am using my digital devices, I don't need to think about my problems. DDS19: I sometimes utilize digital devices to procrastinate or delay).

Consequently, the nine outstanding items epitomize broad digital distraction with three subcategories. Table 2 shows the dimension loading for the leading items (factor loading >.40), as well as eigenvalues, the per cent of variance explained by each dimension, and the mean and standard deviation for each dimension. All the commonalities $\left(\mathrm{h}^{2}\right)$ for the factor analysis fulfilled the smallest prerequisite of being greater than 0.50 and these vacillated from 0.503 to 0.689 . As indicated in Figure 1 below, the scree plot which graphs the eigenvalue against the component number is reminiscent of a three-component model. 


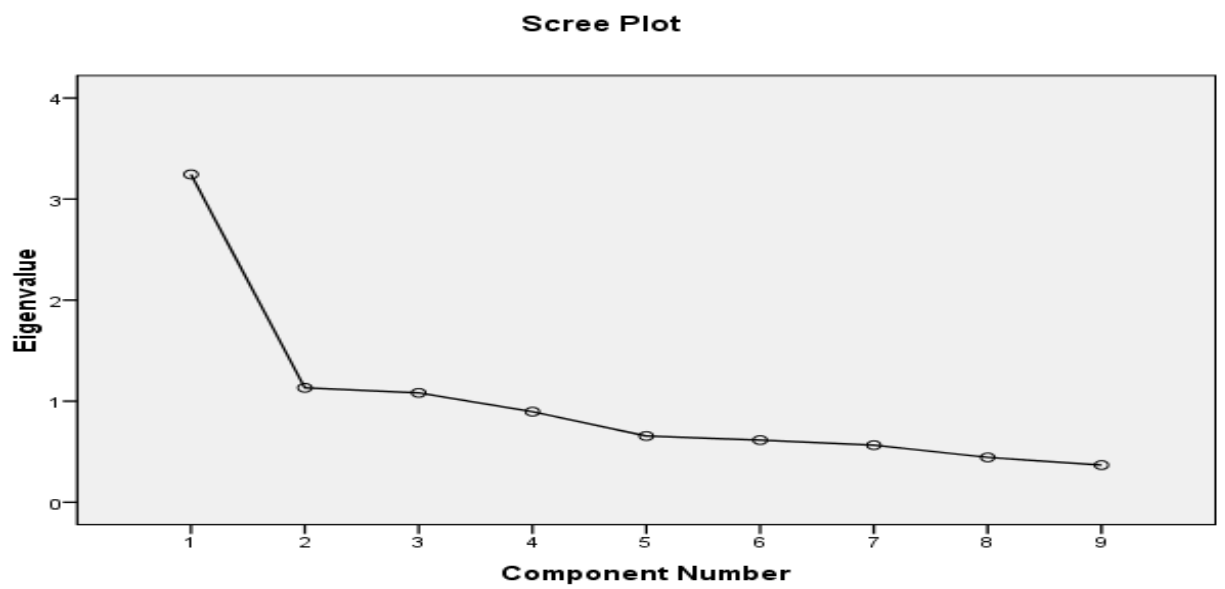

Fig. 1. Cattell scree plot showing the number of components and eigenvalues of the correlation matrix.

Table 2 displayed the factor loadings for the orthogonal three-factor model of DDS. All items loaded .587 and above on their primary factor and none of the secondary loadings exceeded .40 .

Item $\begin{array}{cccccccc}\text { Factor Loadings } & & & & \\ & 1 & 2 & 3 & \mathrm{~h}^{2} & M & \text { SD }\end{array}$

\section{Emotional distraction $(a=.716)$}

DDS11: I feel unenthusiastic to be without my digital devices

(e.g. smartphones)even for a

short time.

DDS20: I often utilize digital devices to dodge doing nasty things.

DDS21: Using digital devices is a way to overlook the things I must do but don't want to do.

\section{Digital addiction $(a=.769)$}

DDS4: The time I spend on my digital devices surfing the internet increases everyday

DDS7: I find myself checking and replying texts, tweets, and emails every time of the day and night-even when it requires stopping other things that I am doing.

DDS9: Sometimes I feel that my use 
of digital devices truly reduces my

productivity at home or school.

.288

.642

.065

.653

$2.51 \quad 1.08$

Distraction by procrastination $(a=.702)$

DDS1: I always find myself expending

more and more time online on my digital

devices (such as a computer, laptop,

tablet and smartphone) than I realize.

.689

3.12

0.93

DDS2: I am fond of carelessly passing

time regularly by gazing at my

digital devices (e.g. smartphones) even

though I have better and more

productive assignments to do.

DDS13: I am not always conscious

of time when I am on any of my digital

devices (e.g. smartphones).

$\begin{array}{llllll}-.114 & .203 & .634 & .574 & 2.51 & 1.05\end{array}$

Scale Mean

$2.44 \quad 2.47 \quad 2.76$

Scale Standard Deviation

$\begin{array}{lll}0.85 & 0.87 & 0.74\end{array}$

Eigenvalue

$3.24 \quad 1.13 \quad 1.08$

Variance explained

$36.05 \quad 12.58 \quad 12.03$

Note: $\quad h^{2}=$ communalities

Extraction Method: Principal Components Analysis.

Rotation Method: Varimax with Kaiser Normalization

Table 2. Item Loadings and Communalities $\left(\mathrm{h}^{2}\right)$ for Principal Components Analysis on DDS Items Depicting Three-Factor Model

\section{Confirmatory Factor Analysis}

The maximum likelihood method was deployed in estimating model parameters. Each time univariate or multivariate non-normality was detected, Satorra-Bentler scaled chi-square statistic $\left(\mathrm{S}-\mathrm{BX}^{2}\right)$, which produces a modification for non-normality of data, was utilized for assessment of model fit (Byrne, 2006). An assessment of the goodness of fit of the conjectured archetypal showed inclinations towards four fit indexes that pertained to diverse facets of archetypal fit: Satorra-Bentler scaled chi-square statistic, Comparative Fit Index (CFI), Tucker Lewis Index (TLI), Root Mean Square Error of Approximation (RMSEA). Hu and Bentler (1999) noted that an archetypal that suitably fits the data would have CFI $\geq .95$, TLI $\geq .95$, RMSEA $\geq .06$ and the standard root mean square residual (SRMR) of 0.08 or below. Also, measurement invariance by gender (male vs. female) was tested in the study. Because the $x^{2}$ is sensitive to covariance matrices in the presence of large sample (Tomarken \& Waller, 2003), the study scrutinized the disparity in the outcome of the CFI and RMSEA to evaluate archetypal fit. However, a gap greater than .01 in the CFI and a gap greater than .015 in the RMSEA showed a significant disparity in archetypal fit for resolving measurement invariance (Chen, 2007). Figures 2 and 3 
below showed the one-factor model and the correlated two-factor model while Figures 3 and 4 exhibited the correlated three-factor model and the higher-order factor model.

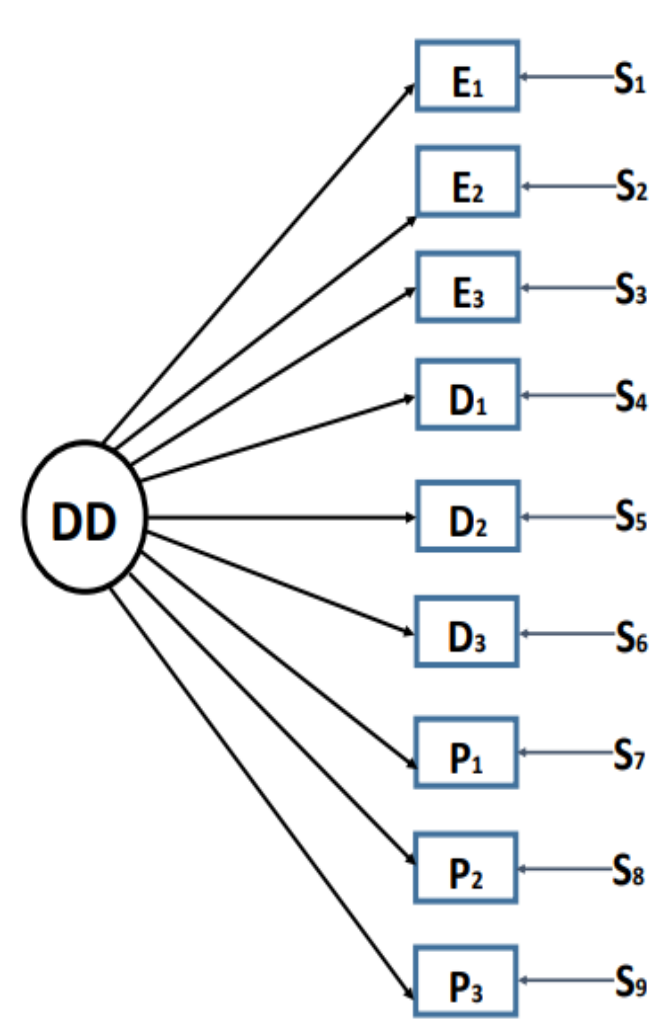

Figure 2: One - factor model

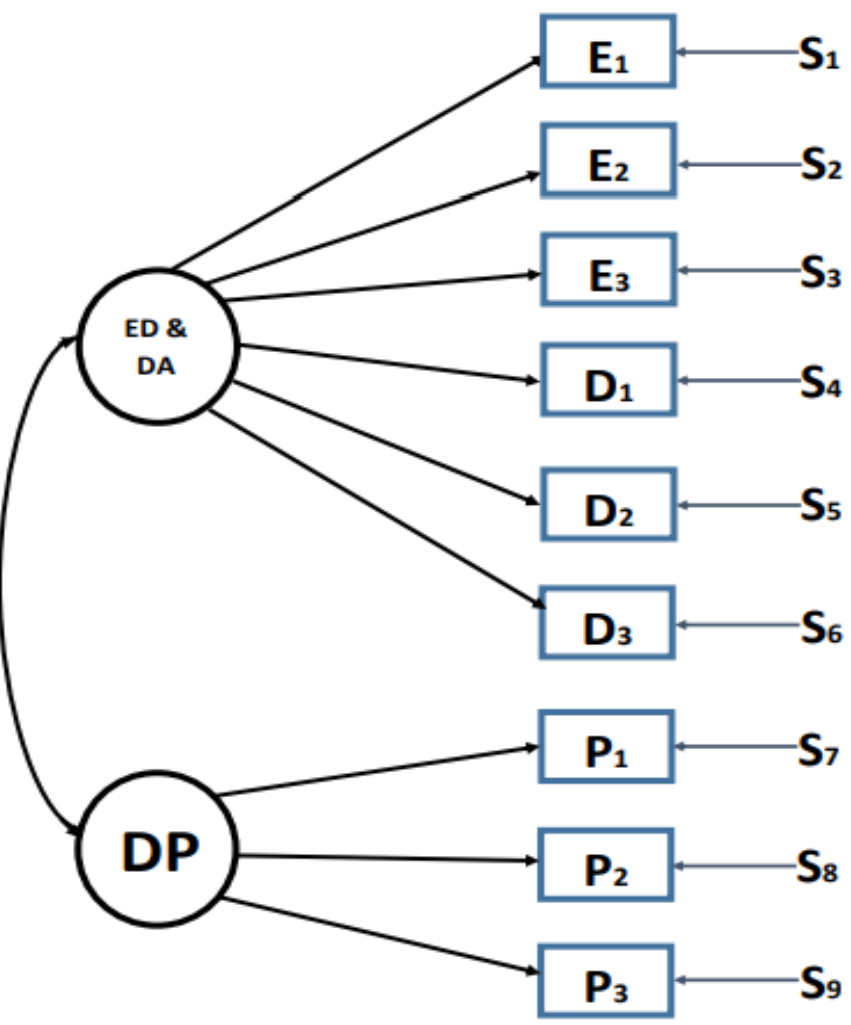

Figure 3: Correlated Two - factor model

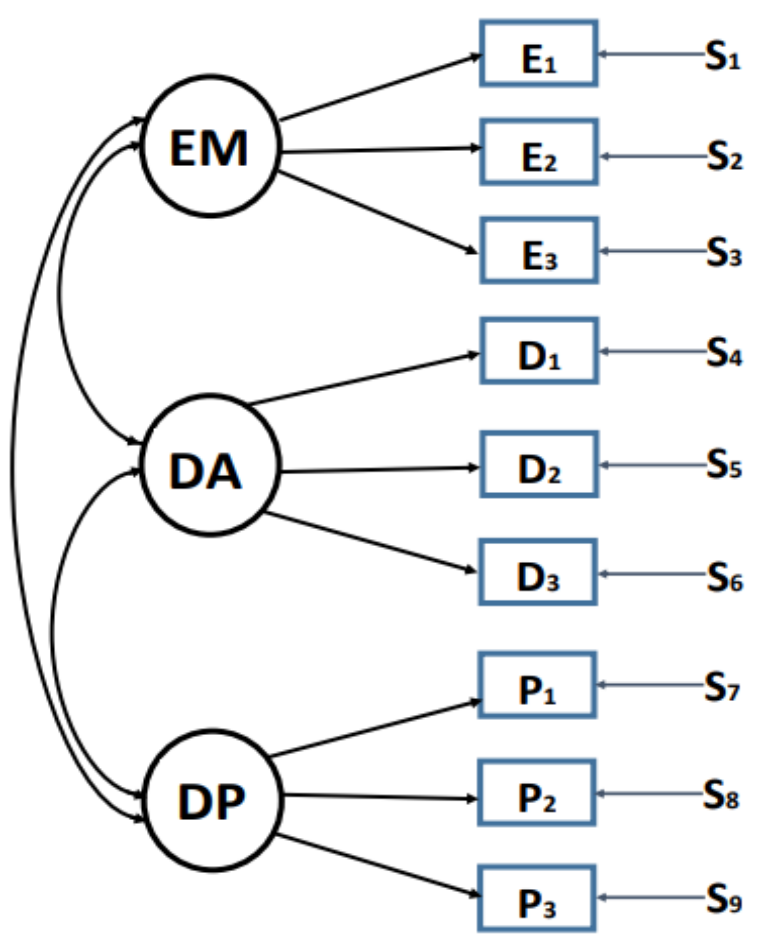

Figure 4: Correlated Three - factor model

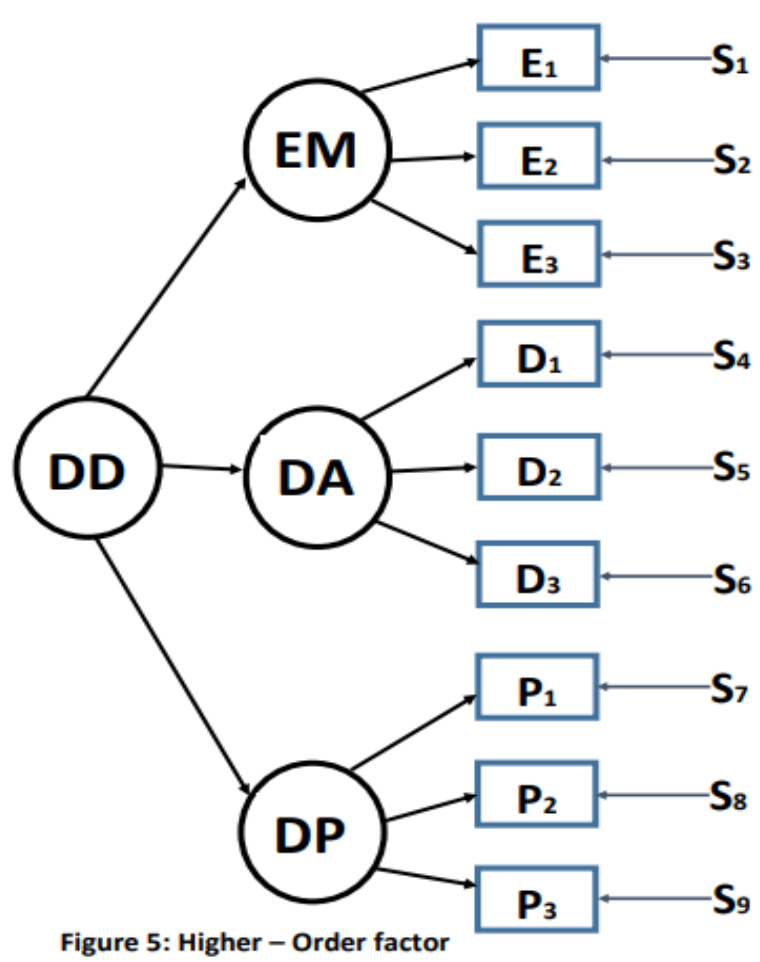

Figure 5: Higher - Order factor 
The fit indices of the four models are indicated in Table 4 below. It is evident in Table 4 that the higher-order factor model and the correlated three-factor model did fit the data sensibly adequately. Although, the $\mathrm{S}-\mathrm{BX}^{2}$ statistic was significant $(p<0.01)$, the additional fit indices indicated realistically adequate fit of the archetypal to the experimental data (the Higher-Order Factor model: CFI $=0.906$, RMSEA $=0.068[90 \%$ confidence interval: $0.063,0.075]$; the correlated three-factor model: CFI $=0.909$, RMSEA $=0.068$ [90\% confidence interval: 0.062 , 0.075]). A comparison of this higher-order factor model and the correlated three-factor model with the two other archetypal revealed very poor fit to the data, as shown in the meaningfully amplified $\mathrm{S}-\mathrm{BX}^{2}$ value, and the model fit indices (the one-factor model: $\mathrm{CFI}=0.780, \mathrm{RMSEA}=0.118$ [90\% confidence interval: $0.111,0.122$; the correlated two-factor model: CFI $=0.798$, RMSEA $=0.107$ [90\% confidence interval: 0.099, 0.112]). Because of the very poor fit of these two representations, they stood rejection and were removed in the analysis. Hence, the three subcategories were different in the dimension structure and so they cannot be joined into one dimension. Since the higher-order factor archetypal and correlated three-factor archetypal fit the data acceptably, an S-BX ${ }^{2}$ disparity test was inaugurated to contrast the fit of these archetypal, thus, producing a significantly meaningful outcome $\left(\Delta \mathrm{S}-\mathrm{BX} \mathrm{x}^{2}=8.20, \Delta \mathrm{df}=1, p<0.05\right)$. This relatively small disparity amid other fit indices indicated that the fit of the two archetypal was the same. The CFI disparity between these two models was 0.003 and this was suggestive of similarity of the fit between the two models. Also, the higher-order factor model showed comparative parsimony and so was chosen as the best-fitting representation that would elucidate the correlations among the three subcategories. All factor estimations in the higher-order model were established to be meaningfully weighty $(p<0.05)$.

\begin{tabular}{llllllll}
\hline Model & S-B ${ }^{2}$ & df & CFI & TLI & SRMR & \multicolumn{2}{l}{ RMSEA [90\% C.I.] } \\
\hline One Factor model & $5356.64 * *$ & 2432 & 0.780 & 0.749 & 0.077 & 0.118 & {$[0.111-0.122]$} \\
Correlated 3-Factor & $3637.12^{* *}$ & 2430 & 0.909 & 0.908 & 0.051 & 0.068 & {$[0.062-0.075]$} \\
Higher-Order Factor & $3685.32 * *$ & 2431 & 0.906 & 0.906 & 0.053 & 0.068 & {$[0.063-0.075]$} \\
Correlated 2-Factor & $5104.63 * *$ & 2434 & 0.798 & 0.799 & 0.075 & 0.107 & {$[0.099-0.112]$} \\
\hline
\end{tabular}

Notes. $* * p<0.01 ;$ C.I. $=$ Confidence Interval.

Table 4. Global fit indices for the four models $(N=2380)$

c. Research Question Three: What are the internal consistency estimate and the test-retest reliability of the digital distraction scale among the pre-service STM teachers in Nigeria?

Internal consistency was determined using Cronbach's alpha. Table 5 showed the results of the internal consistency reliability, and mean and standard deviation for the digital distraction score and each subscale score. Cronbach's alpha vacillated from .702 ('distraction by procrastination' subscale) to .716 ('emotional distraction' subscale) to .769 ('digital addiction' subscale) for the three dimensions while a Cronbach alpha coefficient of 0.872 was computed for the entire scale. Hence, the DDS showed satisfactory internal consistency in the present study. 


\begin{tabular}{llll}
\hline Digital distraction & distraction by procrastination & emotional distraction & digital addiction \\
$\mathbf{a}=.872$ & $\mathbf{a}=.702$ & $\mathbf{a}=.716$ & $\mathbf{a}=.769$ \\
$\mathrm{r}=.812$ & $\mathrm{r}=.690$ & $\mathrm{r}=.708$ & $\mathrm{r}=.713$ \\
Mean $=2.56$ & Mean=2.76 & Mean=2.44 & Mean=2.47 \\
$\mathrm{SD}=0.64$ & $\mathrm{SD}=0.74$ & $\mathrm{SD}=0.85$ & $\mathrm{SD}=0.87$ \\
$\mathrm{~N}=2380$ & $\mathrm{~N}=2380$ & $\mathrm{~N}=2380$ & $\mathrm{~N}=2380$ \\
\hline
\end{tabular}

Table 5. Internal consistency (a) and test-retest ( $r$ ) reliabilities for the pre-service STM teacher-report digital distraction scale.

Test-retest reliability was determined using Pearson moment correlation coefficient. As contained in Table 5, the test-retest reliability vacillated from .690 ('distraction by procrastination' subscale) to .708 ('emotional distraction' subscale) to .713 ('digital addiction' subscale) for the three dimensions while a value of 0.812 was computed for the entire scale. Thus, the DDS exhibited adequate testretest reliability and this means that the coefficients of congruence were generally strong in the study.

d. Research Question Three: Does the digital distraction scale show measurement invariance with regards to the gender of the pre-service STM teachers in Nigeria?

The metric invariance held by gender for digital distraction items as the constrained model with equal factor loadings all fit better than the unconstrained (baseline) models with larger CFI and TLI, and smaller RMSEA as can be seen on Table 6.

\begin{tabular}{|c|c|c|c|c|c|c|c|c|}
\hline Model & $\mathrm{df}$ & CFI & TLI & RMSEA $(90 \% \mathrm{CI})$ & $\Delta \mathrm{x}^{2}$ & $\Delta \mathrm{df}$ & $\Delta$ CFI & $\triangle \mathrm{RMSEA}$ \\
\hline$G(M \vee . F) 1 . B M$ & 4620 & $7524.01 * .953$ & .942 & $.057(.056, .058)$ & & & & \\
\hline 2. MI & 4830 & $7630.34 * .972$ & .970 & $.046(.044, .047)$ & 106.33* & 210 & - & - \\
\hline
\end{tabular}

Note. $\mathrm{G}=$ Gender; $\mathrm{M}=$ Males; $\mathrm{F}=$ Females; $\mathrm{V}=$ Versus; $\mathrm{BM}=$ Baseline model; $\mathrm{MI}=$ Metric Invariance

${ }^{*} \mathrm{p}<.001$. - indicates that the more constrained model provides better fit than the less constrained model and thus difference test cannot be performed; Comparative Fit Index (CFI), Tucker Lewis Index (TLI), Root Mean Square Error of Approximation (RMSEA).

Table 6. Test of measurement invariance for the pre-service STM teacher-report digital distraction scale.

e. Research Question Three: What are the relationships among distraction by procrastination, emotional distraction, digital addiction and aggregate digital distraction of pre-service STM teachers?

Table 7 showed the results of the relationship among the distraction by procrastination, emotional distraction, digital addiction and aggregate digital distraction of pre-service STM teachers. As shown in the table, that there was a significant moderate positive correlation between the preservice STM teachers' distraction by procrastination and emotional distraction $(r=.412, p<.01)$, and digital addiction $(r=.398, p<.01)$. There was a significant moderately positive relationship between pre-service STM teachers' emotional distraction and digital addiction $(r=.459, p<.01)$. Besides, there was a significantly high correlation between each dimension of digital distraction and 
aggregate digital distraction. The low correlations among the dimensions of digital distraction are anticipated in that they represent a distinct construct.

\begin{tabular}{lllll}
\hline & 1 & 2 & 3 & 4 \\
\hline 1. Emotional distraction & 1 & & \\
2. Digital addiction & $.459^{*}$ & 1 & & \\
3. DIstraction by procrastination & $.412^{* *}$ & $.398^{* *}$ & 1 & 1 \\
4. Aggregate Digital distraction & $.803^{* *}$ & $.805^{* *}$ & $.744^{*}$ & 2.56 \\
Mean & 2.44 & 2.47 & .76 & .64 \\
SD & .85 & .87 & .74 & 2380 \\
$\mathrm{~N}$ & 2380 & 2380 & 2380 & \\
\hline
\end{tabular}

**Correlation is significant at the .01 level (2-tailed).

Table 7. Correlations matrix for the relationship between distraction by procrastination, emotional distraction, digital addiction and aggregate digital distraction of pre-service STM teachers

\section{Discussion}

A large proportion of the pre-service STM teachers exhibited high digital distraction in the present study. The high digital distraction in the general sample could be ascribed to the fact most of the pre-service STM teachers are digital natives born in this $21^{\text {st }}$ century of a digital renaissance. This finding agreed with the view of Seemiller (2017) that students found it difficult to power down their digital devices during lectures in the classrooms thereby pointing to their ubiquitous use of digital devices for both educational and non-educational activities. The high digital distraction in the preservice STM teachers in this study showed their doggedness in staying connected at all times to their digital devices not minding the negative cost of disrupting social norms. Majority of the preservice STM teachers felt unenthusiastic to be without their digital devices even for a short time as they often utilize these devices in dodging doing nasty things. To the pre-service STM teachers in this study, spending time on digital devices increased daily as they use them as a way to overlook the things they must do but don't want to do. They found themselves checking and replying texts, tweets, and emails every time of the day and night-even when it requires stopping other things that they are doing thereby decreasing their productivity at home or in school. Majority of the preservice STM teachers remarked that they are fond of carelessly passing time regularly by gazing at their digital devices even though they have better and more productive assignments to do. Most times the pre-service STM teachers are not always conscious of time when they are on their digital devices.

Reducing pre-service STM teacher digital distraction in classroom learning is important for educational and expert accomplishment in STM occupations. Regrettably, educationalists and scholars lack consistent and useable assessment tools to exactly evaluate and measure pre-service STM teachers' digital distraction during STM learning undertakings. In the present study, a crucial impact is made via the evolvement of a strong and multidimensional pre-service STM teacherreport survey tool for measuring pre-service STM teachers' digital distraction in class. This study is unique in the literature in that it is the first to demonstrate that a higher-order model fit the digital distraction factorial configuration well. This higher-order model indicates that pre-service STM 
teacher digital distraction is categorized through an inclusive digital distraction paradigm, as well as three distinctive dimensions: distraction by procrastination, emotional distraction, and digital addiction. By explaining the inclusive digital distraction and several specific factors of pre-service STM teachers' digital distraction, one will be capable of identifying the categories of digital distraction that most perfectly forecast STM-dependent learning results. With this identification of factors, one is capable of testing for the additive and interactive impacts among several dimensions. Besides, the researcher will be able to explore the relationship between STMdependent outcomes and the inclusive digital distraction paradigm, and the distinctive role of the particular factors to STM results that are different from the inclusive digital distraction paradigm.

The present study has shown support for the multidimensional paradigm of digital distraction in pre-service STM teachers learning. In this study, three hypothetically discrete dimensions of digital distraction have been established and these do not concur with viewing digital distraction on a continuum relatively than utilizing a factorial viewpoint. A multidimensional standpoint on preservice STM teacher digital distraction enables a wealthier depiction of how pre-service STM teachers perform, sense, deliberate, and hang out with colleagues in STM classrooms, relatively than seeing each of the factors distinctly. Viewing digital distraction as a multidimensional paradigm could help researchers to ponder on the aftermath of each factor of digital distraction distinctly on STM outcomes. A higher-order model that comprises distraction by procrastination, emotional distraction, and digital addiction, enables a good fit for the data in pre-service STM teacher-report. The three dimensions of digital distraction constitute a common factor of inclusive digital distraction which depicts the joint variances pooled by the three dimensions of the digital distraction. Also, each dimension of pre-service STM teacher digital distraction exemplifies specific factors, which depict their distinctive variances, far higher than the inclusive factor of pre-service STM teacher digital distraction. Not examined in the present study, these specific factors could be used to differentially predict educational attainment and scholastic ambitions, autonomous of the inclusive digital distraction factor. In all, this study supports the idea that distraction by procrastination, emotional distraction, and digital addiction are not only theoretically correlated to one another at the inclusive paradigm level, but also depict different and distinctive paradigms.

The good test-retest reliabilities of the digital distraction scale and its subscales showed that the scores on the scales are not variable over time and that the scales are not sensitive to alterations in the learning milieu. This study offers experimental proof backing up the measurement invariance via gender. Thus, this result connotes that the subject matter of most items construed equally across gender group. Creating measurement invariance is important to evolving an exceedingly generalizable metric of digital distraction that researcher can deploy to forecast educational outcomes for both male and female pre-service STM teachers. It may be noted that some sets of pre-service teachers for instance women may be disadvantaged for possessing higher digital distraction in STM learning. Generating measurement invariance to enable that assessment of digital distraction functions equally through clusters permits academics to produce further suitable appraisals between clusters like males and females.

\section{Conclusion}

Despite the findings of this study, the study is not without limitations. First, the over-reliance on survey method is one limitation that may reduce one's capability to holistically investigate the digital distraction as other methods such as interviews and observations may be more useful in the construct exploration. Second, this study failed to answer the question of how each dimension of digital distraction could explain academic outcomes in STM and how the dimensions help to form a pre-service teacher general digital distraction. With this multidimensional scale, it should be 
possible to ascertain the association between each dimension of digital distraction and latent outcomes in hypothetical representations and generate diverse pre-service teacher digital distraction profiles. Besides, this multidimensional scale can be deployed in academic milieus as mediations for identifying definite dimensions of digital distraction among pre-service STM teachers with high global digital distraction. In divergence, an inclusive assessment of pre-service teacher digital distraction can be enough for putting to test policy pertinent queries associated with the results of digital distraction in STM learning. This study has been able to objectively provide experimental proof supportive of the factorial validity of the digital distraction scale. It is anticipated that this assessment tool will be useful for researchers exploring the background predictors and educational imports of digital distraction in STM learning contexts. Finally, it is hoped that this tool will be handy for educators interested in isolating pre-service STM teachers at risk of high digital distraction which may cause lack of respect and privation of courtesy for instructors and personal distraction in the classroom.

\section{Acknowledgements}

We would like to acknowledge the participation of the pre-service STM teachers in this study and for making themselves available for the research study. We appreciate their contributions to the success of the study.

\section{References}

Adams, D. (2006). Wireless laptops in the classroom (and the sesame street syndrome). Communications of the ACM, 49, 25-27.

Attia, N. A., Baig, L., Marzouk, Y. I, \& Khan, A. (2017). The potential effect of technology and distractions on undergraduate students' concentration. Pakistani Journal of Medical Science, 33(4), 860-865. doi: https://doi.org/10.12669/pjms.334.12560.

Awofala, A. O. A. (2012). Development and factorial structure of students' evaluation of teaching effectiveness scale in mathematics. Cypriot Journal of Educational Sciences, 7(1), $33-44$.

Awofala, A. O. A. (2017). Assessing senior secondary school students' mathematical proficiency as related to gender and performance in mathematics in Nigeria. International Journal of Research in Education and Science, 3(2), 488-502.

Awofala, A. O. A., \& Fatade, A. O. (2015). Validation of the domains of creativity scale for Nigerian preservice science, technology, and mathematics teachers. Electronic Journal of Research in Educational Psychology, 13(1), 131-150.

Burns, S., \& Lohenry, K. (2010). Cellular phone use in class: Implications for teaching and learning a pilot study. College Student Journal, 44, 805-810.

Byrne, B. M. (2006). Structural equation modelling with EQS: Basic concepts, applications, and programming (2nd ed.). Mahwah, New Jersey: Psychology Press.

Chen, F. F. (2007). The sensitivity of goodness of fit indexes to lack of measurement invariance. Structural Equation Modeling: A Multidisciplinary Journal, 14, 464-504.

Chen, L., Nath, R., \& Insley, R. (2014). Determinants of digital distraction: A cross-cultural investigation of users in Africa, China and the U.S. Journal of International Technology and Information Management, 23(3), 145-171. 
Davis, R. A., Flett, G. L., \& Besser, A. (2002). Validation of a new scale for measuring problematic Internet use: Implications for pre-employment screening. CyberPsychology \& Behavior, 5(4), 331-345.

Duncan, D. K., Hoekstra, A. R., \& Wilcox, B. R. (2012). Digital devices, distraction, and student performance: Does in-class cell phone use reduce learning? Astronomy Education Review, 11(1), 1-4.

Frisby, B. N., Sexton, B., Buckner, M., Beck, A-C. \& Kaufmann, R. M. (2018). Peers and instructors as sources of distraction from a cognitive load perspective. International Journal for the Scholarship of Teaching and Learning, 12(2), 1-10. Available at: https://doi.org/10.20429/ijsotl.2018.120206.

Gebre, E., Saroyan, A., \& Bracewell, R. (2014). Students' engagement in technology-rich classrooms and its relationship to professors' conceptions of effective teaching. British Journal of Educational Technology, 83-96.

Greenfield, D. (2017). Digital distraction test. The Centre for Internet and Technology Addiction.

Hefferman, V. (2010). The attention-span myth. New York Times Magazine, November 11, 22.

Hegedus, S., \& Roschelle, J. (Eds.). (2013). Learning important mathematics from contextualization and networked collaboration-A review of the SimCalc vision and contributions: Democratizing Access to Important Mathematics. Journal for Research in Mathematics Education, 125-129.

Hu, L. T., \& Bentler, P. M. (1999). Cutoff criteria for fit indexes in covariance structure analysis: Conventional criteria versus new alternatives. Structural Equation Modeling: A Multidisciplinary Journal, 6, 1-55.

Junco, R., \& Cotton, S. (2011). Perceived academic effects of instant messaging use. Computers \& Education, $56,370-378$.

Kraushaar, J. M., \& Novak, D. C. (2010). Examining the effects of student multitasking with laptop during the lecture. Journal of Information Systems Education, 21(2), 241-251.

Martin, L. (2011). Teaching business statistics in a computer lab: Benefits or distraction? Journal of Education for Business, 86(6), 326-331.

McCoy, B. (2013). Digital distractions in the classroom: Student classroom use of digital devices for non-class related purposes. Journal of Media Education, 4(4), 5-14. Retrieved from http://en.calameo.com/read/000091789af53ca4e647f

McCoy, B. R. (2016). Digital distractions in the classroom phase ii: student classroom use of digital devices for non-class related purposes. Faculty Publications, College of Journalism \& Mass Communications, 90, 143. http://digitalcommons.unl.edu/journalismfacpub/90

Melerdiercks, K. (2005). The dark side of the laptop university. Journal of Ethics, 14, 9-11.

O'bannon, B., \& Thomas, K. (2014). Teacher perceptions of using mobile phones in the classroom: Age matters! Computers \& Education, 15-25.

Ogunniyi, M. A. (2004). Development, validation and use of university students' evaluation of teaching effectiveness scale (USETES). Unpublished Doctoral Dissertation. The University of Ibadan, Ibadan, Nigeria.

Ophir, E., Nass, C., \& Wagner, A. D. (2009) Cognitive Control in Media Multi-Taskers. Proceedings of the National Academy of Sciences, 106(37), 15583-15587

PR Newswire. (2013). Digital distraction: CIO survey: Tech gadgets contributing to a decline in workplace etiquette. PR Newswire, May 7, 2013.

Rajeshwar, K. (2010). Too connected in a wireless world? Interface, 19(4), 3.

Rutten, N., van Joolingen, W., \& van der Veen, J. (2012). The learning effects of computer simulations in science education. Computers \& Education, 58(1), 136-153.

Seemiller, C. (2017). Curbing digital distractions in the classroom. Contemporary Educational Technology, 8(3), 214-231 
Sullivan, A., Johnson, B., Owens, L., \& Conway, R. (2014). Punish them or engage them? Teachers' views of unproductive student behaviours in the classroom. Australian Journal of Teacher Education, 39(6), 4356.

Sweller, J., van Merrienboer, J. J. G., \& Paas, F. G. W. C. (1998). Cognitive architecture and instructional design. Educational Psychology Review, 10, 251-296. doi:10.1023/A:1022193728205.

Tomarken, A. J., \& Waller, N. G. (2003). Potential problems with "well fitting" models. Journal of Abnormal Psychology, 112, 578-598.

Wen, M. L., Tsai, C. C., Lin, H. M., \& Chuang, S. C. (2004). Cognitive-metacognitive and content-technical aspects of constructivist Internet-based learning environments: A LISREL analysis. Computers \& Education, 43, 237-248.

Wood, E., Zivcakova, L., Gentile, P., Archer, K., Pasquale, D., \&. Nosko, A. (2012). Examining the impact of offmultitasking with technology on real-time classroom learning. Computers \& Education, 58, 365-374. 